\title{
LOCALIZATION OF PORPHYRINS IN BONE TISSUE IN A CASE OF PORPHYRIA CUTANEA TARDA
}

BY

\author{
K. G. PAUL, A. ENGSTRÖM, AND B. ENGFELDT \\ From the Department of Biochemistry, the Nobel Institute of Medicine, and the Department for Physical Cell Research, \\ the Karolinska Institute, Stockholm
}

(RECEIVED FOR PUBLICATION NOVEMBER 18, 1952)

It is well known that porphyrins can be adsorbed on to precipitates of calcium salts, and adsorption can take place under the most varying conditions. Thus, it has been shown that in certain diseases porphyrins are found to be adsorbed on to urinary sediments of calcium phosphates (Garrod, 1892 ; Dobriner, 1936 ; Sveinsson, Rimington, and Barnes, 1949) and on to the bone and tooth tissue in mammals.

\section{Historical Review}

Derrien (1924) demonstrated that in normal newborn animals the already ossified part of the skeleton, as well as the teeth of young guinea-pigs, had a pink fluorescence. Mackey and Garrod (1922, 1926) and Ashby (1926) observed pigmentation of teeth in porphyria congenita. In the case described by Mackey and Garrod, the dentine zone around the pulp cavity gave a bright fluorescence. The rest of the dentine and the enamel gave a weak fluorescence. Fourie (1936) found no pigmentation of the enamel in two cases of animal ochronosis, although the dentine and cement were coloured. In another case of the same disease, Fikentscher (1931) observed an uneven distribution of the pigmentation of Haversian and interstitial lamellae in bone tissue. The walls of the osteocytes appeared pink under ultra-violet light. An annular arrangement of darker and more lightly stained rings, as seen in transverse sections, has been described (Teutschlaender, 1914 ; Borst and Königsdörffer, 1929; Fourie, 1936). Rimington (1936) considered the phenomenon as depending upon "accumulations of pigment deposits during periods of arrested bone growth rather than periodic variations in the intensity of the disease."

Fischer, Hilmer, Lindner, and Pützer (1925) isolated a uroporphyrin (m.p. of methyl ester $285^{\circ}$ C.) from the skeleton of a case of porphyria congenita (Petry). Fink (1931) and Rimington
(1936) isolated uroporphyrin from bones in cases of animal ochronosis. No coproporphyrin was found. By means of decarboxylation, Rimington, in collaboration with Mertens, identified his porphyrin as uroporphyrin I. Its methyl ester melted at $293^{\circ} \mathrm{C}$.

Fraenkel (1924) injected a crude porphyrin mixture, obtained from Petry urine, into growing animals. The skeletons acquired a brown pigmentation. In adult animals no brown pigmentation was found except in the callus around fractures. Königsdörffer (1929) found that uroporphyrin but not copro-, meso-, proto-, or haemato-porphyrin stained the bone tissue. Fikentscher, Fink, and Emminger (1933) confirmed this observation. They also examined morphologically the localization of injected uroporphyrin. Macroscopically, the metaphyses and the growth zones of the epiphyses fluoresced more strongly than other parts of the bone tissue. In non-decalcified sections it was seen that the cartilaginous, non-mineralized areas were free from porphyrins. The appearance of pink fluorescence coincided with the beginning of the mineralization. Completely mineralized columnae cartilagiae were very rich in porphyrins.

In the case studied by Mackey and Garrod (1926), ossification was retarded between $4 \frac{1}{2}$ and $9 \frac{1}{2}$ years of age. The thoracic skeleton of Petry was found to be thin and fragile, and the fingers were distorted (Borst and Königsdörffer, 1929). Fikentscher et al. (1933) noticed retarded growth in their animals after the prolonged administration of porphyrins, especially deuteroporphyrin. The incidental observations mentioned above seem to be of interest in connexion with the investigation presented in this paper.

\section{Material and Aim of the Investigation}

Our bone material comes from a man, M.M., 72 years of age, who had suffered from porphyria diagnosed at the age of 65 . He had been repeatedly 
in hospital for treatment for the porphyria. It should be pointed out that the necropsy showed severe cirrhosis of the liver, which is a recognized cause of coproporphyrinuria. The complete case history, together with points of general medical and pathological interest, will be given in a separate publication.

The aim of the present investigation was to see in which structures the porphyrins were localized in the bone tissue from this case of porphyria cutanea tarda. The nature of the porphyrin localized in the bone tissue was identified by various chemical methods. Furthermore, the localization of the porphyrins as determined by fluorescence microscopy were correlated with the content of mineral salts in the different structures of the bone. The amount of mineral salts in the microscopic structures of the bone were demonstrated by $x$-ray microradiography.

\section{Analytical Techniques}

Preparation of Bone Samples.-The study of the microscopic localization of porphyrins in bone tissue requires relatively thin sections. The topography and local concentrations of the porphyrins must not be changed during the preparation. With a sharp, rotating saw slices $0.2 \mathrm{~mm}$. thick were cut from the compact and spongy bone of the femora. The slices were ground on glass plates to a final thickness of 50 to $200 \mu$. The greater thickness for the spongy bone was necessary because of its fragility. During the grinding process light petroleum was used. Samples taken from the femur of a normal individual of the same age and prepared in an identical way served as a comparison.

Localization of Porphyrins.-As intact (non-decalcified) bone sections of 50 to $200 \mu$ in thickness were studied, the ordinary transmitting fluorescence microscope could not be used to localize the porphyrins. Instead, the light from a powerful ultra-violet lamp (HgU, 120 W X4, "Wood's lamp") was collected by a quartz lens, and directed down on the specimen. The fluorescence of the surface of the bone section was observed in a stereoscopic microscope with a long working distance (Zeiss type opton). When the red fluorescence of the porphyrin was studied in the bluish background a red-orange filter (OG5) was inserted between the sample and the microscope objective. Attempts to photomicrograph the weak fluorescence of the sample were not very successful, as very long exposure times were required.

Microradiography.-The different structures in bone have varying contents of mineral salts, mainly hydroxylapatite, as has been shown by Amprino and Engström (1952) and by Amprino (1952). The content of mineral salts in the ground section of the bone tissue was determined by microradiography. Essentially, the technique described by Engstıöm and Wegstedt (1951) was used. In order to obtain a sharp image, the distance between the sample and the fine-grain photographic emulsion must be as small as possible. The sections of spongy bone were not completely flat, and therefore, in order to get good contact between the sample and the film, a special vacuum camera was used (Sherwood, 1947). $\frac{\vec{\sigma}}{2}$ A Machlett AEG 50 tube with $1 \mathrm{~mm}$. Be-window served as the $x$-ray source. This tube was run at $8 \mathrm{kV}$, $\frac{\bar{\sigma}}{\bar{\omega}}$ giving $x$ rays with a short wavelength limit of $1.5 \AA$. $\frac{\pi}{\sigma}$ The thick specimens were microradiographed with $\stackrel{\odot}{\complement}$ Siemens's "crystalloflex II" diffraction unit, run at ڤ 25 to $45 \mathrm{kV}$. The microradiographs were registered ? either on Lippman emulsion or Eastman Kodak ? spectroscopic plate 649 . These photographic emulsions $\overrightarrow{\vec{\omega}}$ have a resolving power of about 1,000 lines per $\mathrm{mm}$. $\stackrel{\omega}{\circ}$ The microradiographs were processed according to standard procedures. Enlargements of the microradiographs were obtained by photomicrography. is Kodak O 250 plates were used. The enlarged microradiographs were copied on normal paper.

The Chemical Identification of Skeletal Porphyrin.- 음 A piece of the femur diaphysis, $15 \mathrm{~cm}$. long, was sawn longitudinally, cleaned carefully with a knife and sand- 3 paper, and cut into $2-3 \mathrm{~mm}$. pieces (total weight $65 \mathrm{~g}$.). 离 The material was defatted with alcohol and ether, dried at room temperature, then left in $650 \mathrm{ml}$. of $15 \%(\mathrm{w} / \mathrm{v})$ $\mathrm{HCl}$ for two days. A yellow fluorescence (in addition to the red) was observed, which was apparently unchanged after the alcohol and ether extractions but vanished almost instantaneously when the slices were immersed in acid. Debris (non-fluorescent) was separated with glass wool. After neutralization with sodium acetate $\frac{2}{\varnothing}$ the debris was shaken for two hours with ether-acetic $\varrho$ acid in the proportions $10: 1$, but no porphyrins were $\overrightarrow{\vec{O}}$ detected in a $5 \% \mathrm{HCl}$ extract of the ether fraction. The 3 main acid fraction was diluted to $1,500 \mathrm{ml}$., and adjusted $\supset$ to $\mathrm{M}-1.75 \mathrm{HCl}$ with alkali. A slight precipitate was filtered off. Adsorption on talc (Nicholas and Comfort, 1949) was attempted, but all pigments passed through $\frac{\text { ? }}{0}$ the column. Sodium acetate was therefore added to

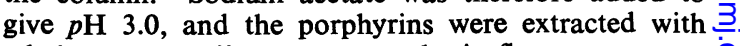
ethyl acetate until no more porphyrin fluorescence was $\delta$ seen. The remaining aqueous phase was carefully 3 examined for porphyrins but with negative results. 응 Thus, after the addition of a 1 in 10 volume of $25 \%$ ? (w/v) $\mathrm{HCl}$ no porphyrin bands could be detected in a $\frac{7}{0}$ $20 \mathrm{~cm}$. layer. Therefore, the bone tissue contained no uroporphyrin I. A final ethyl acetate extraction from the $N$ $p \mathrm{H} 3.0$ solution did not contain any porphyrin. The combined ethyl acetate extracts were then shaken $\mathcal{N}$ repeatedly with $15 \% \mathrm{HCl}$. The acid was diluted with water to M-1.6 HCl, and passed through a $40 \times 10$ O $\mathrm{mm}$. talc column. The porphyrins were now quantitatively adsorbed. After washing with $\mathrm{HCl}$, water, a 1:1 dilution $(\mathrm{v} / \mathrm{v})$ of acetone and water, the porphyrins $\infty$ were eluated with acetone containing $1 \%$ concentrated ${ }^{+}$ $\mathrm{HCl}$. After the removal of acetone in vacuo, the remaining $\mathrm{HCl}\left(2.9 \mathrm{ml}\right.$.) was $\mathrm{M}-0.9$. The maximum $\frac{P}{\mathbb{D}}$ extinction of the Soret band in a dilution $0.100 \mathrm{ml} .+\stackrel{\odot}{\odot}$ $3.50 \mathrm{ml}$. M-1 $\mathrm{HCl}$ was found to be $\mathrm{E}=\log \frac{\mathrm{I}_{\mathrm{o}}}{\mathrm{I}}=\frac{\mathbb{Q}}{2}$ 0.548 at $406 \mathrm{~m} \mu$. In terms of uroporphyrin this corre- 
sponds roughly to a total quantity of $90 \mu \mathrm{g}$. from the $65 \mathrm{~g}$. of bone tissue (Rimington and Sveinsson, 1950).

The acid was removed in an air current at room temperature and the dry residue esterified with $6 \mathrm{ml}$. methanol $+0.3 \mathrm{ml}$. concentrated sulphuric acid. The mixture was left for 24 hours at room temperature, and then refluxed for five hours. The ester was taken up in chloroform in the usual way, washed, dried, and put on to an alumina grade IV (Nicholas, 1951) column $(100 \times 10 \mathrm{~mm}$. $)$. With chloroform no substance migrated down the column, as checked by frequent observations in ultra-violet light. Thus, the material put on the column did not contain either two- or four-carboxylic porphyrins. With chloroform-methanol (100: 0.5) one single, pink band passed down. Above the pink zone the column was practically free from pink fluorescence, except at the top, where a small orange-red fluorescent zone remained. The latter was not further analysed. All the pigment was collected in $8 \mathrm{ml}$. of effluent.

The absorption spectrum (aetiotype) of the eluted material in chloroform-methanol (100:0.5) showed maxima at 625.9, 573.9, 535.8 , and $502.5 \mathrm{~m} \mu$ (reversion spectroscope). Uroporphyrin III ester has the bands 625,570 , 535, and $502 \mathrm{~m} \mu$ (Nicholas and Rimington, 1951).

The ester crystallized as very thin and long needles, not hair-like and curved, from chloroform-methanol. The material had a strong tendency to crystallize with a melting point (Kofler-Block) of $266^{\circ}$. The mother liquor was almost colourless. The ester of an ethyl acetate soluble uroporphyrin ("Waldenström ester") from the urine melted at 254 to $255^{\circ}$. In cases where the original bone material had not been carefully cleaned, and was therefore contaminated with bone marrow, an additional four-carboxylic porphyrin spot appeared on paper chromatography.

The melting point of the uroporphyrin ester from bone $\left(266^{\circ}\right)$ is close to the value $\left(264^{\circ}\right)$ by Nicholas and Rimington (1951) for pure uroporphyrin III octamethyl ester. The uroporphyrin I octa-ester melts at $293^{\circ}$ (Rimington, 1936; Rimington and Miles, 1951). This indicates that the uroporphyrin was of series III. Thus, the osseous tissue contained only uroporphyrin, most probably of series III.

\section{Results}

The only porphyrin that could be detected in the bone tissue of the investigated case of porphyria cutanea tarda was probably uroporphyrin III. However, four-carboxylic porphyrins were found in material from other sources, e.g., bone marrow, ascites fluid, and liver tissue.
When the bone sections prepared by grinding under light petroleum were examined under the fluorescence microscope it was noted that certain Haversian systems showed a strong pink to red fluorescence, which stood out clearly against the blue fluorescence of the rest of the bone. The same 


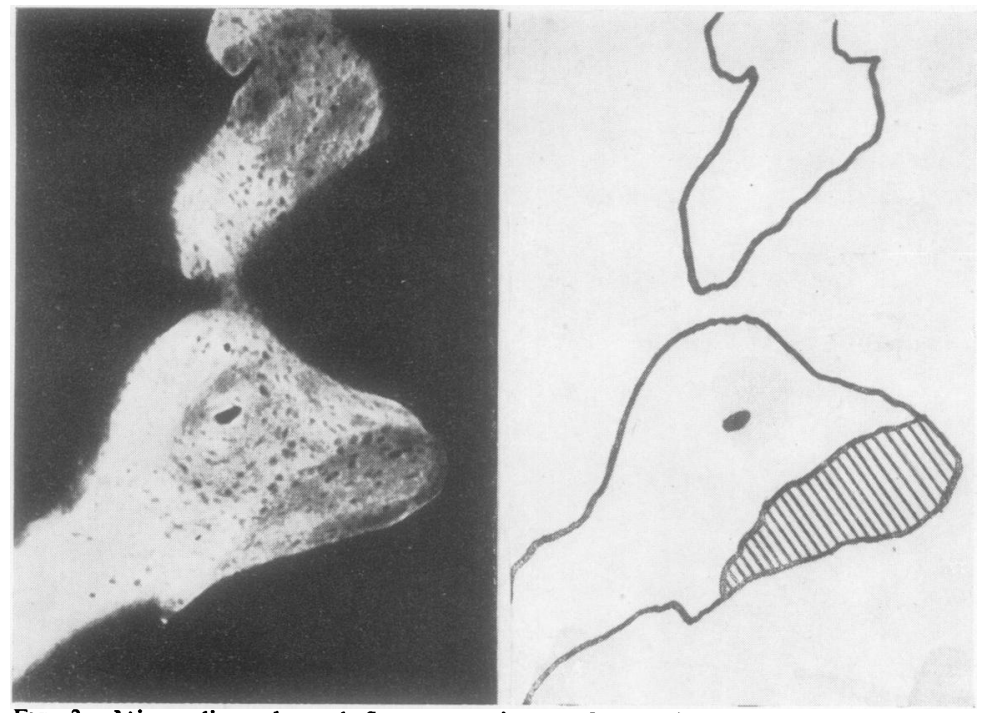

FIG. 3.-Microradiographs and fluorescence image of a section from spongy bone tissue showing the localization of the porphyrin.

sections were subjected to microradiography in order to determine the amount of mineral salts in different Haversian systems. A comparison between the fluorescence of the sample and its $x$-ray absorption showed that the fluorescent substance (uroporphyrin III) was limited to the Haversian systems with a medium content of mineral salts. These experimental findings are illustrated in Figs. 1, 2, and 3 . In the microradiographs it can be clearly seen that the different Haversian systems have highly varying contents of mineral salts. To the right of each microradiograph there are drawn schematic illustrations in which the red fluorescence is indicated by the hatched areas. It can be seen that the fluorescence is clearly confined to areas with a certain content of mineral salts both in the compact and cancellous bone.

Another type of fluorescence was also observed. Thin rings in certain Haversian systems showed a strong yellow fluorescence (indicated in the schematic drawing in Fig. 3 by the dotted area). The nature of the yellow fluorescence, which is confined to a thin ring in young Haversian systems, was not clarified.

From the investigation we concluded that the uroporphyrin was localized in bone structures with mineral salt contents falling within a narrow range. Structures with very high or very low mineral content contained no uroporphyrin.

\section{Discussion}

The chemical and histochemical investigations mentioned in the historical summary had been made on material from cases of porphyria congenita or from animals with ochronosis. Porphyrin pigmentation of bone and tooth tissue has been considered as a characteristic feature of porphyria congenita, but has not been found in porphyria acuta and porphyria cutanea tarda, although all three types excrete eight-carboxylic porphyrins. The case of porphyria recently described by Gray, Rimington, and Thomson (1948) possessed certain features of all three types of porphyria. In this case an additional etherinsoluble porphyrin, which differed from the uroporphyrins, was excreted. This patient did not have pigmented teeth.

The difference between the three types of porphyria as regards the pigmentation of bone and teeth tissue is evident from the fact that the manifestations of porphyria congenita (and of animal ochronosis) appear at the earliest ages, while porphyria acuta has a maximum frequency at 20 to 30 years of age (Waldenström, 1937), and porphyria cutanea tarda appears still later in life.

In the case described in this publication, the bones appeared quite normal to the naked eye in normal light, and it may therefore be that the presence of porphyrins has been overlooked in the skeletons of similar cases.

The continuous resorption and deposition of mineral salts in the bone tissue is influenced by several factors. One of the important functions of the skeleton is to regulate the ionic milieu of the mammalian organism. By resorption of bone, ions can be released to the blood stream, and by deposition of mineral salts can be fixed to the bone tissue. The peculiar type of crystal lattice that exists in the inorganic part of the bone tissue, crystalline hydroxylapatite with imperfect zones, is well suited to serve the ion-regulating mechanism (Amprino and Engström, 1952). From a crystallographical point of view, various additional ions can be incorporated in the lattice.

As the absolute age of a Haversian system cannot be determined with any accuracy at present, there are several possible explanations for the precise localization of the porphyrins. The amount of porphyrin adsorbed on to calcium phosphate precipitates is dependent upon the concentration 


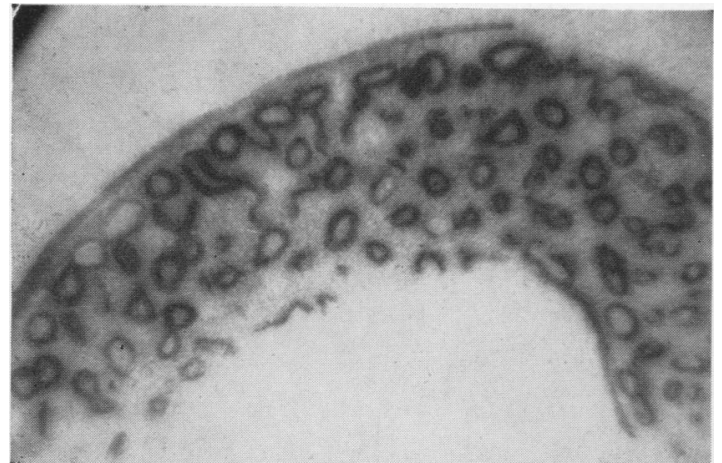

FIG. 4.-Autoradiograph from a section of femur from a dog given radioactive phosphate intraperitoneally three hours before being sacrificed. The uptake of radioactive phosphate varies from one Haversian system to the other. The highest uptake takes place in those Haversian systems which have the lowest content of mineral salt (the young systems).

of free phosphate ions at the moment of precipitation (Sveinsson et al., 1949). One possible explanation for the present results is that the ionic milieu and probably the amount of free phosphate ions is different in different Haversian systems during their life span. This explanation is in agreement with experiments concerning isotope uptake of different Haversian systems, cf. Fig. 4 (Engfeldt, Engström, and Zetterström, 1952). Another possibility is that the porphyrins are deposited only in rapidly growing bone tissue, such as young Haversian systems, which have a rapid increment of mineralization. They remain thus localized as these systems grow older and become more mineralized. If this hypothesis is true, we would expect to find porphyrins also in the youngest systems. In the present investigation this was not the case. However, the uroporphyrin production decreased towards the end of the life of the patient, and the concentration of uroporphyrin may have been too low to give any detectable deposition in the youngest systems.
The cyclic variations of the excretion or production of porphyrins in certain porphyrias may also affect the deposition. Therefore it is possible that the concentration of porphyrins in the blood is sufficient only to give detectable fluorescence in those few Haversian systems which are well suited for the deposition.

\section{Summary}

In a case of porphyrinuria cutanea tarda only uroporphyrin III has been isolated from the bone tissue. This porphyrin is microscopically localized to certain Haversian systems and structures where the ionic milieu is well suited for the deposition. The precise localization of the porphyrins is discussed from the point of view of bone physiology.

\section{REFERENCES}

Amprino, R. (1952). Z. Zellforsch., 37, 144.

And Engström, A. (1952). Acta anat., Basel, 15, 1.

Ashby, H. T. (1926), Ouart. J. Med. 19, 375.

Borst, M., and Königsdörffer, H. (1929). Untersuchungen ueber Porphyrie. Hirzel, Leipzig.

Derrien, E. (1924). C. R. Soc. Biol., Paris, 91, 634

Dobriner, K. (1936). J. biol. Chem., 113, 1.

Engfeldt, B., Engström, A., and Zetterström, R. (1952). Biochim. biophys. Acta, $8,375$.

Engström, A., ’and Wegstedt, L. (1951). Acta radiol., Stockh., 35, 345.

Fikentscher, R. (1931). Virchows Arch. path. Anat., 279, 731.

Fink, H., and Emminger, E. (1933). Ibid., 287, 764.

Fink, H. (1931). Z. physiol. Chem., 197, 193. Fischer, H., Hilmer, H., Lindner, F., and Pützer, B. (1925). Hoppe-
Seyl. Z., 150,44 .

Fourie, P. J.'J. (1936). Onderstepoort J. vet. Sci., 7, 535

Fraenkel, E. (1924). Virchows Arch. path. Anat., 248, 125.

Garrod, A. E. (1892). J. Physiol., 13, 598.

Gray, C. H., Rimington, C., and Thomson, S. (1948). Quart. J. Med., n.s. 17, 123

Königsdörffer, H. (1929). Quoted from Borst and Königsdörffer. Mackey, L., and Garrod, A. E. (1922). Quart. J. Med., 15, 319.

- (1926). Ibid., 19, 357.

Nicholas, R. E. H. (1951). Biochem. J., 48, 309. and Comfort, A. (1949). Ibid., 45, 208.

and Rimington, C. (1951). Ibid., $50,194$.

Rimington, C. (1936). Onderstepoort J. vet. Sci., 7, 567.

- and Miles, P. A. (1951). Biochem. J., 50, 202.

- and Sveinsson, S. L. (1950). Scand. J. clin. Lab. Invest., 2, 209.

Sherwood, H. F. (1947). Rev. sci. Instrum., 18, 80

Sveinsson, S. L., Rimington, C., and Barnes, H. D. (1949). Scand J. clin. Lab. Invest., 1, 2.

Teutschlaender, O. R. (1914). Virchows Arch. path. Anat., 217, 393.

Waldenström, J. (1937). Acta med. scand., Suppl. 82, p. 1 . 